\title{
Synthesis of Cellulose Nanocrystals (CNCs) from Brewer's Spent Grain Using Acid Hydrolysis: Characterization and Optimization
}

\author{
Bisrat Yihun Matebie, ${ }^{1}$ Belachew Zegale Tizazu $\mathbb{D D}^{1}$ 'Aseel A. Kadhem, ${ }^{2}$ \\ and S. Venkatesa Prabhu ${ }^{1}$ \\ ${ }^{1}$ Department of Chemical Engineering, Addis Ababa Science and Technology University, 16417 Addis Ababa, Ethiopia \\ ${ }^{2}$ Ministry of Education, Wasit Education Directorate, Wasit Governorate, Kut City, Iraq \\ Correspondence should be addressed to Belachew Zegale Tizazu; belachew.zegale@aastu.edu.et
}

Received 30 July 2021; Accepted 3 September 2021; Published 26 September 2021

Academic Editor: Lakshmipathy R

Copyright (c) 2021 Bisrat Yihun Matebie et al. This is an open access article distributed under the Creative Commons Attribution License, which permits unrestricted use, distribution, and reproduction in any medium, provided the original work is properly cited.

\begin{abstract}
This study is aimed at utilizing brewery's spent grain (BSG) byproduct for the synthesis of cellulose nanocrystals (CNCs) using acid hydrolysis and optimizing the hydrolysis parameters (hydrolysis time, temperature, liquid-solid ratio, and acid concentration). Alkali and bleaching treatment were done to remove hemicellulose and lignin from BSG. Optimization process was performed using central composite design (CCD) to obtain optimum value of cellulose nanocrystal (CNC) yield. The maximum cellulose nanocrystal (CNC) yield of $43.24 \%$ was obtained at optimum hydrolysis conditions of $50^{\circ} \mathrm{C}, 51 \mathrm{wt} \%$ acid concentration, $41 \mathrm{~min}$, and liquid-solid ratio of $19 \mathrm{ml} / \mathrm{g}$. The raw brewery spent grain; alkali-treated fiber, bleached fiber, and obtained CNC were characterized using scanning electron microscopy (SEM), XRD, particle analyzer, FTIR, and differential scanning calorimeter (DSC). The characterization results indicated that the obtained cellulose nanocrystal (CNC) has rod-like whisker shape with crystallinity of $76.3 \%$ and an average particle size of $309.4 \mathrm{~nm}$.
\end{abstract}

\section{Introduction}

Currently, cost minimization and environmental awareness issues become a common agenda for researchers [1]. Developing a new green material from renewable biomass is one of a promising ways to solve cost and environmental pollution-related issues. Renewable biomasses commonly have three parts which are cellulose, lignin, and hemicellulose [2]. Cellulose is the most abundantly existing biopolymer which mainly exists in plant cell wall, and it also found in animals such as tunicates, bacteria, sea mosses, and algae [3]. The estimated annual production of cellulose in the world is $1.5 \times 10^{12}$ ton [1]. Even if cellulose is attractive due to its biodegradable, renewable, and nontoxic properties, it has a limitation towards its use in the area of various applications due to low strength, poor thermal stability, and high-water absorption properties [2].

Currently, nanotechnology is an interesting and promising area to improve the performance and application of cel- lulose by destroying the amorphous region and such kind of material called cellulose nanocrystals (CNCs) [4]. Different raw materials were used for isolation of nanocrystalline cellulose such as corn husk [5], rice straw [4], and bamboo pulp using acid hydrolysis [1]. For the present study, brewery spent grain (BSG) is a renewable biomass source for cellulose to extract cellulose nanocrystals using acid hydrolysis.

Brewery's spent grain (BSG) is a lignocellulosic residue produced from brewery industry [6]. Beer is the fifth most consumed beverage in the world behind tea, soft drinks, milk, and coffee with the annual world beer production of exceeding 1.34 billion hectoliters [7]. BSG is generated after the raw barley grain passes through the process of malting, mashing, fermentation, and filtration [8]. The common raw materials for brewery's spent grain include barley malt cereals, cereal straws of wheat, buckwheat, and rice [6]. The statistics of FAO shows that the world annual cropping of barely seed is 8.3 million metric tons in 2010 [9]. Barley brewery spent grain mainly composed of cellulose, hemicellulose, lignin, 
protein, ash, and extractives [8]. Thus, barely BSG covers $85 \%$ of the total beer production byproducts [10]. BSG readily exists with high volume and low cost [11] and has a high potential for the isolation of cellulose for further synthesis of different derivatives such as carboxymethyl cellulose [12] and cellulose nanocomposites [13].

Nanocrystalline cellulose (cellulose nanocrystals) is renewable resource which has short rod like or whisker shape with the size of $2-100 \mathrm{~nm}$ diameter and $100-500 \mathrm{~nm}$ length with the composition of $100 \%$ cellulose in the crystalline region [14]. The world annual mass production of nanocellulose is increasing and estimated up to more than $9 \times 10^{3}$ tons of nanocellulose per year [15]. Currently, the researcher interest is growing up to produce nanocrystalline cellulose due to an excellent property such as better mechanical strength, high surface area and aspect ratio, nontoxicity, crystallinity, biocompatibility, and biodegradability. For this reason, it is a potential renewable green substrate for many applications ranging from medicinal use such as xylitol and pullulan production for dental caries and diabetes treatment [11] to producing of composite materials, food packaging, foams, aerogels, textile, oxygen-barrier layers, and optically transparent functional materials [1].

Different methods have been used to synthesize highly purified nanocrystals from cellulosic materials, including the chemical method, mainly carried out by acid hydrolysis [4], enzyme-assisted hydrolysis [15], and mechanical treatments, such as high-pressure homogenizing [16], grinding [17], and ultrasonication [3] as well as a combination of two or several of the abovementioned methods. In recent years, acid hydrolysis has become a promising method with nanotechnology to modify the physical and chemical properties of cellulose. Acid hydrolysis produces nanocrystalline cellulose by hydrolyzing the hydroxyl functional group of cellulose at specific parametric condition of temperature, time, and acid [18].

This study is aimed at isolating cellulose nanocrystals (CNCs) from a renewable, cheap, and currently underutilized raw material, i.e., barley brewery spent grain (BSG). BSG was pretreated using several mechanical and chemical processes, including grinding, sieving, alkali treatment, and bleaching. Cellulose nanocrystals (CNCs) were produced by sulfuric acid hydrolysis followed by ultrasonication (SNC). The resulting CNC products were characterized by scanning electron microscopy (SEM), X-ray diffraction (XRD), Fourier-transform infrared spectroscopy (FTIR), particle size analyzer, and differential scanning calorimeter (DSC).

\section{Materials and Methods}

2.1. Materials. Brewery spent grain (BSG) was obtained from local Heineken brewery factory in Addis Ababa, Ethiopia. All analytical grade chemicals such as hydrogen peroxide (30\%) for bleaching, sodium hydroxide (98\%) for alkali treatment, and sulfuric acid (98\%) for synthesis of cellulose nanocrystals were obtained from Himedia, India, and Merck, Germany.
2.2. Isolation of Cellulose from Brewery Spent Grain (BSG). Raw brewery spent grain was washed with distilled water successively and dried using air circulating oven (TD-1315) at $50^{\circ} \mathrm{C}$ for 12 hours. After drying its size, it was reduced to $0.5 \mathrm{~mm}$ using grinder. Oversize spent grain particle was then separated using sieve ( $500 \mu \mathrm{m}$ mesh size) for further pretreatment processes such as acid, alkali, and bleaching treatments.

2.3. Acid and Alkali Treatments. The BSG was initially treated with $1.25 \%$ (wt/v) sulfuric acid, $120^{\circ} \mathrm{C}$ for 17 minutes at solid-liquid ratio of $1: 10(\mathrm{~g}: \mathrm{ml})$ to solubilize the hemicellulose. The acid-treated spent grain was dried using air circulating oven for 12 hours at $50^{\circ} \mathrm{C}$. It was then milled using mortar pestle. Following acid treatment, the alkali treatment was employed two times to remove the hemicellulose completely. During alkali treatment, 2\% sodium hydroxide with solid-liquid ratio of $1: 20(\mathrm{~g}: \mathrm{ml})$ was used. This mixture was heated using magnetic heater for $2 \mathrm{hr}$ at $80^{\circ} \mathrm{C}$. The mixture was successively washed with distilled water and separated using centrifuge at $4000 \mathrm{rpm}$ to remove the black liquor and to achieve a neutral $\mathrm{pH}$. It was then dried for 12 hours at $50^{\circ} \mathrm{C}$ in the oven to remove the moisture content $[12,19]$.

2.4. Bleaching Treatment. Bleaching treatment was done after alkali treatment to remove lignin and the remaining hemicellulose content of the brewery spent grain. The bleaching treatment was done in three steps: (1) 5\% hydrogen per oxide and $0.07 \mathrm{M}$ sodium hydroxide with equal parts $(1: 1)$ was mixed. The solid liquid ratio used during bleaching treatment was $1: 30(\mathrm{~g}: \mathrm{ml})$. This mixture was heated using magnetic stirrer heater for $40 \mathrm{~min}$ at $70^{\circ} \mathrm{C}$. It was then successively washed with distilled water and separated using centrifuge at $4000 \mathrm{rpm}$ until a neutral $\mathrm{pH}$ was obtained. (2) The above bleaching procedure was repeated. Subsequently, it was dried using oven for 18 hours at $50^{\circ} \mathrm{C}$ to remove the moisture. (3) $0.25 \mathrm{M}$ sodium hydroxide, at a temperature of $70^{\circ} \mathrm{C}$, was mixed with the pulp for one hour at the solid liquid ratio of $1: 30(\mathrm{~g}: \mathrm{ml})$. It was then repeatedly washed with distilled water and separated using centrifuge at $4000 \mathrm{rpm}$ until a neutral $\mathrm{pH}$ was obtained. It was then dried using oven for 18 hours at $50^{\circ} \mathrm{C}$ to remove the moisture [19].

2.5. Synthesis of Cellulose Nanocrystals (CNCs). CNCs were synthesized from brewery spent grain fiber using acid hydrolysis based on the previous methods reported in the literature with some modification $[20,21]$. The brewery spent grain samples were treated with 47,51 , and $55 \%(\mathrm{wt} / \mathrm{v})$ sulfuric acid, at a temperature of 45,50 , and $55^{\circ} \mathrm{C}$ and treatment time of 35,40 , and 45 minutes at a solid-liquid ratio of $1: 15,1: 20$, and $1: 25(\mathrm{~g}: \mathrm{ml})$ into $200 \mathrm{ml}$ beaker. The mixture was placed on magnetic stirrer (MS-H280-PRO) at $800 \mathrm{rpm}$ to homogenize it. The hydrolysis reaction was ceased by placing the reaction mixture in an ice bath, and the excessive sulfuric acid was removed by successive distilled water washing and centrifugation (Pro-Analytical C2004) for $10 \mathrm{~min}$ at $4000 \mathrm{rpm}$. The successive centrifugation resulted colloidal suspension. This colloidal suspension 
TABLE 1: Independent variables and levels used in the CCD for acid hydrolysis of BSG cellulose.

\begin{tabular}{lccccc}
\hline \multirow{2}{*}{ Variables } & \multirow{2}{*}{ Coding } & \multirow{2}{*}{ Unit } & \multicolumn{3}{c}{ Levels } \\
& & & -1 & 0 & 1 \\
\hline Time & $\mathrm{X} 1$ & Minute & 35 & 40 & 45 \\
Sulfuric acid concentration & $\mathrm{X} 2$ & $\%$ & 47 & 51 & 55 \\
Temperature & $\mathrm{X} 3$ & ${ }^{\circ} \mathrm{C}$ & 45 & 50 & 55 \\
Liquid solid ratio & $\mathrm{X} 4$ & $\mathrm{ml} / \mathrm{g}$ & 15 & 20 & 25 \\
\hline
\end{tabular}

was neutralized using $0.5 \mathrm{~N}$ sodium hydroxide to achieve a neutral $\mathrm{pH}$. Sonication was then performed at $60 \mathrm{~W}$ for 10 minutes to reduce the aggregation of nanoparticles. The suspension was dried using freeze dryer for two days.

2.6. Experimental Design. The central composite design (CCD) of response surface methodology was used to investigate the effect of and optimize the acid hydrolysis parameters on the yield of CNC production. The yield was investigated depending on four factors, i.e., the upper and lower levels of the parameters, viz., acid concentration, hydrolysis time, temperature, and liquid-solid ratio, were fixed following a preliminary experiment conducted one variable at a time (OVAT) for each parameter as shown in Table 1. Three-level-four-factor central composite design (CCD) was used for optimizing the factors and the response of the experiment in which 26 runs were conducted. After those 26 experiments were conducted, the Design-Expert Software 12.0.0 was used to statistically analyze the data and obtain suitable equation for synthesis of cellulose nanocrystals using acid hydrolysis.

\subsection{Analytical Methods}

2.7.1. Scanning Electron Microscopy (SEM) Analysis. SEM (FEI INSPECTF50) was used to determine the surface morphology of untreated, alkali treated, bleached BSG, and isolated $\mathrm{CNC}$ with an accelerating voltage of $10 \mathrm{kV}$. Those samples were prepared in dried form and scanned the surfaces with a focus beam of electrons. The samples were placed on black carbon tape, and the image was captured with various magnification level and working distance.

2.7.2. Fourier-Transform Infrared Spectroscopy (FTIR). FTIR (iS50ABX) was used for determination of change in the chemical functional group. FTIR spectra of raw BSG, alkali-treated fiber, bleached fiber, and CNC samples were recorded with range of 400 to $4000 \mathrm{~cm}^{-1}$ with 32 resolution. The samples were prepared in powder form for analysis. Then, the prepared samples were pressed into a pellet and analyzed in spectral region.

2.7.3. X-Ray Diffraction (XRD). XRD (BTX-528) was used for the determination of sample crystallinity (which shows cellulose amorphous region is hydrolyzed or not). The samples were dried using oven for $24 \mathrm{~h}$ at $50^{\circ} \mathrm{C}$ to remove the moisture content completely. After this, the dried samples were prepared in powder form and scanned in $2 \theta$ using $\mathrm{XRD}$ by varying the range from 5 to $60^{\circ}$ and operated at
TABLE 2: RSM-CCD experimental design matrix and response data.

\begin{tabular}{|c|c|c|c|c|c|c|}
\hline Std & Run & $\begin{array}{l}\text { Time } \\
(\min )\end{array}$ & $\begin{array}{c}\text { Temperature } \\
\left({ }^{\circ} \mathrm{C}\right)\end{array}$ & $\begin{array}{c}\text { Sulfuric } \\
\text { acid } \\
(\mathrm{wt} \%)\end{array}$ & $\begin{array}{l}\text { Liquid-solid } \\
\text { ratio }(\mathrm{ml} / \mathrm{g})\end{array}$ & $\begin{array}{c}\text { Yield } \\
(\%)\end{array}$ \\
\hline 21 & 1 & 40 & 50 & 47 & 20 & 41.61 \\
\hline 19 & 2 & 40 & 45 & 51 & 20 & 41.77 \\
\hline 11 & 3 & 35 & 55 & 47 & 25 & 37.89 \\
\hline 14 & 4 & 45 & 45 & 55 & 25 & 36.78 \\
\hline 9 & 5 & 35 & 45 & 47 & 25 & 36.18 \\
\hline 4 & 6 & 45 & 55 & 47 & 15 & 37.83 \\
\hline 2 & 7 & 45 & 45 & 47 & 15 & 35.31 \\
\hline 25 & 8 & 40 & 50 & 51 & 20 & 43.02 \\
\hline 13 & 9 & 35 & 45 & 55 & 25 & 38.34 \\
\hline 12 & 10 & 45 & 55 & 47 & 25 & 38.51 \\
\hline 24 & 11 & 40 & 50 & 51 & 25 & 42.79 \\
\hline 10 & 12 & 45 & 45 & 47 & 25 & 36.91 \\
\hline 22 & 13 & 40 & 50 & 55 & 20 & 42.33 \\
\hline 8 & 14 & 45 & 55 & 55 & 15 & 36.96 \\
\hline 3 & 15 & 35 & 55 & 47 & 15 & 35.73 \\
\hline 5 & 16 & 35 & 45 & 55 & 15 & 36.61 \\
\hline 7 & 17 & 35 & 55 & 55 & 15 & 36.74 \\
\hline 26 & 18 & 40 & 50 & 51 & 20 & 42.95 \\
\hline 16 & 19 & 45 & 55 & 55 & 25 & 37.74 \\
\hline 18 & 20 & 45 & 50 & 51 & 20 & 41.55 \\
\hline 17 & 21 & 35 & 50 & 51 & 20 & 41.14 \\
\hline 20 & 22 & 40 & 55 & 51 & 20 & 42.46 \\
\hline 6 & 23 & 45 & 45 & 55 & 15 & 37.42 \\
\hline 15 & 24 & 35 & 55 & 55 & 25 & 37.58 \\
\hline 1 & 25 & 35 & 45 & 47 & 15 & 34.42 \\
\hline 23 & 26 & 40 & 50 & 51 & 15 & 42.46 \\
\hline
\end{tabular}

an acceleration voltage of $40 \mathrm{kV}$, using $\mathrm{Cu} \mathrm{K} \alpha$ radiation. The crystallinity index can be determined using Equation (1):

$$
\% \text { crystallinity }(\mathrm{CI})=\frac{\text { Area of crystalline peaks }}{\text { Total area of peaks }} \times 100 \text {. }
$$

Crystalline size can be determined using Scherrer equation as follows:

$$
D=\frac{\kappa \lambda}{d \cos \theta}
$$

where $D$ is crystalline size, $\lambda$ is constant radiation with value of $0.154060 \mathrm{~nm}, k$ is crystallite shape factor, $d$ is FWHM, and $\theta$ is angle (in radian).

2.7.4. Differential Scanning Calorimeter (DSC). The thermal behavior of raw cellulose and extracted cellulose nanocrystals were analyzed using differential scanning calorimeter (SKZ1052B). During measurement, $20 \mathrm{mg}$ of each sample was prepared for analysis. The weighed sample was placed 
TABLE 3: ANOVA for quadratic regression model.

\begin{tabular}{lccccc}
\hline Source & SS & DF & MS & $F$ value & $P$ value \\
\hline Model & 191.58 & 14 & 13.68 & 75.17 & $<0.0001$ \\
A-X1 & 1.07 & 1 & 1.07 & 15.85 & 0.0340 \\
B-X2 & 3.29 & 1 & 3.29 & 18.09 & 0.0014 \\
C-X3 & 2.07 & 1 & 2.07 & 11.39 & 0.0062 \\
D-X4 & 4.74 & 1 & 4.74 & 26.05 & 0.0003 \\
AB & 0.3108 & 1 & 0.3108 & 21.71 & 0.0180 \\
AC & 1.39 & 1 & 1.39 & 17.62 & 0.0186 \\
AD & 1.04 & 1 & 1.04 & 15.69 & 0.0362 \\
BC & 3.30 & 1 & 3.30 & 18.14 & 0.0013 \\
BD & $6.250 E-06$ & 1 & $6.250 E-06$ & 25.00 & 0.00954 \\
CD & 0.7613 & 1 & 0.7613 & 14.18 & 0.0456 \\
A $^{2}$ & 13.55 & 1 & 13.55 & 74.42 & $<0.0001$ \\
$B^{2}$ & 5.99 & 1 & 5.99 & 32.93 & 0.0001 \\
$C^{2}$ & 7.19 & 1 & 7.19 & 39.47 & $<0.0001$ \\
$D^{2}$ & 2.66 & 1 & 2.66 & 14.64 & 0.0028 \\
Residual & 2.00 & 11 & 0.1821 & & 0.0859 \\
Lack of fit & 2.00 & 10 & 0.2000 & 81.64 & Not significant \\
Pure error & 0.0025 & 1 & 0.0025 & & \\
Total & 193.58 & 25 & & & \\
\hline
\end{tabular}

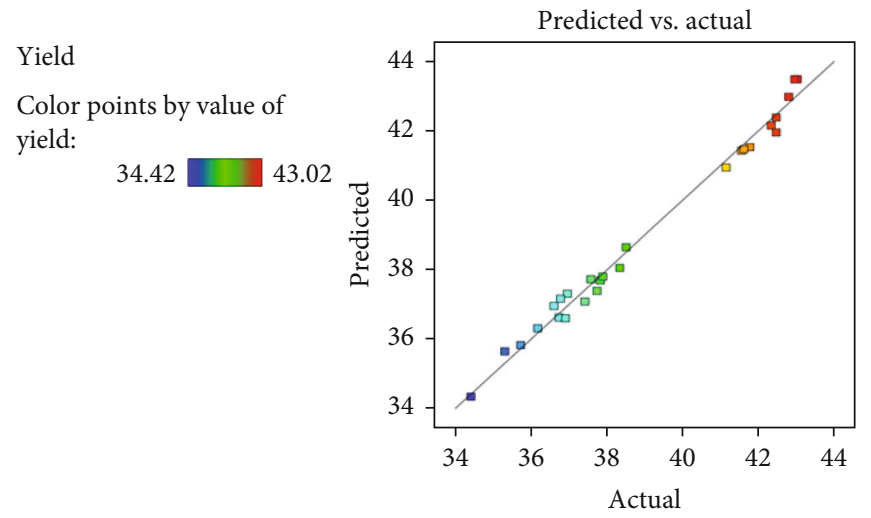

Figure 1: Experimental vs. predicted yield in the regression model.

in platinum crucible and heated from room temperature to $400^{\circ} \mathrm{C}$ for 40 minutes with a heating rate of $10^{\circ} \mathrm{C} \mathrm{min}{ }^{-1}$.

2.7.5. Particle Size Analyzer. Malvern zetasizer nano (ZE3600) was used to measure the particle size distribution of obtained cellulose nanocrystals (CNCs). The sample was prepared by diluting the CNC suspension using distilled water, and size distribution measurement was performed at room temperature, and time taken for thermal equilibrium was 170 seconds. The measurements were conducted in triplicate.

\section{Results and Discussion}

3.1. Cellulose Nanocrystal (CNC) Yield Optimization Using Central Composite Design. Response surface methodology using central composite design was used to modeling, analysis, and optimizing the yield of CNC. RSM was used in the way of determining the level and optimum combination of the relevant factors which gives a desired cellulose nanocrystal yield. Multiple regression equation was performed to express the relationship between factors and performance measures. Each relevant factor (time, temperature, concentration, and liquid solid ratio) has been tested on three levels. The dependent variable used as response parameter was the cellulose nanocrystal yield. All experiment was carried out three times to minimize the experimental error. Synthesis yield of CNC was varied in the range of $34.42-43.02 \%$ as shown in Table 2.

The quadratic model was chosen from the several possible models of Design expert12 for the prediction of the given yield. The model equation that relates cellulose nanocrystal 


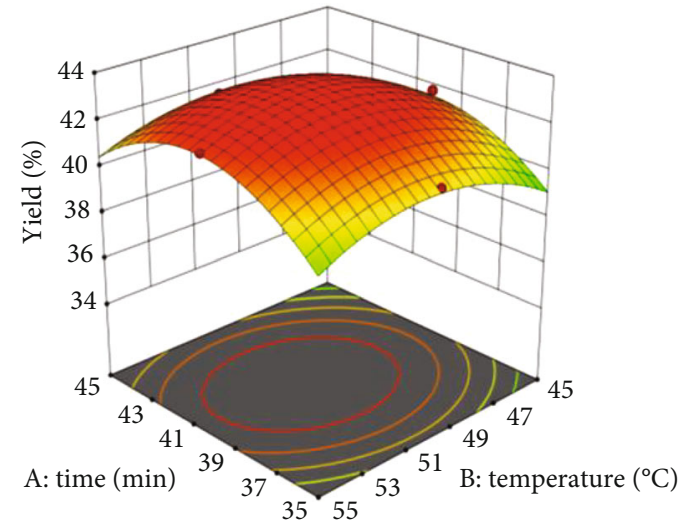

(a)

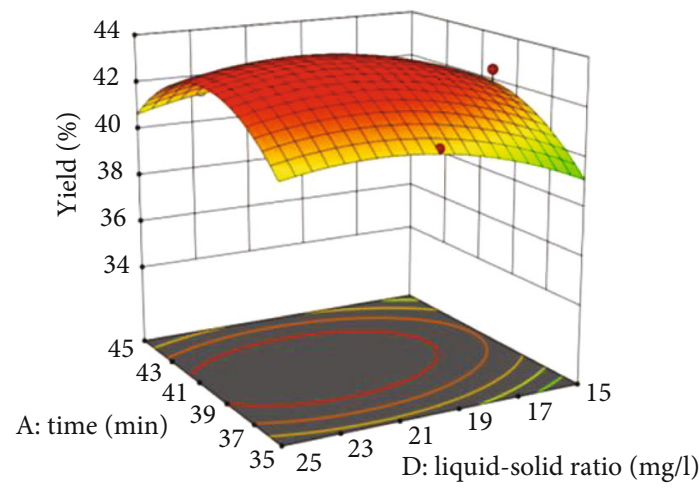

(c)

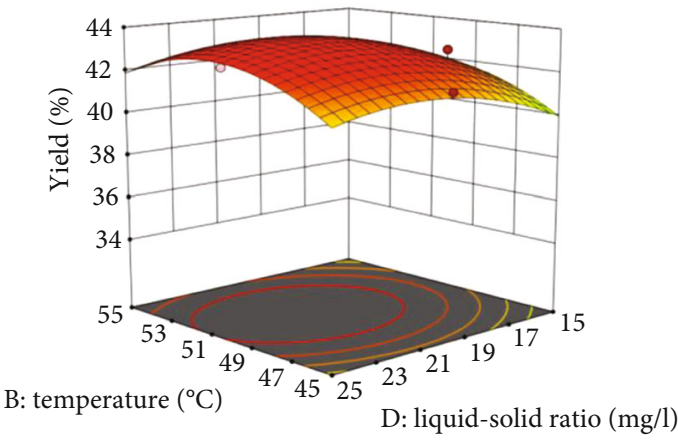

(e)

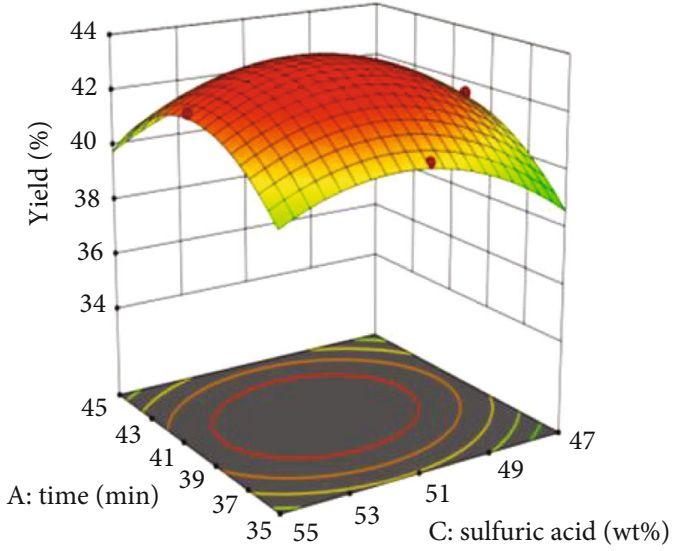

(b)

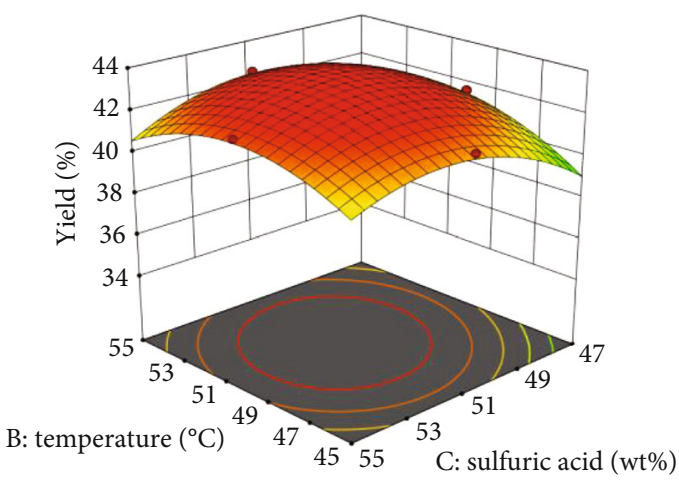

(d)

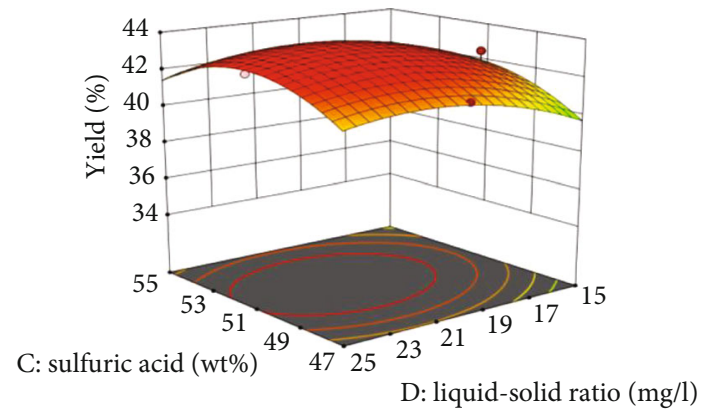

(f)

FIGURE 2: Response surface and contour plots showing interaction effect of parameters on CNC yield.

yield to the acid hydrolysis parameters in terms of coded factors is given in Equation (3). The equation is significant for predicting the given yield and effect of each parameter.

$$
\begin{aligned}
\text { Yield }(\%)= & +43.48+0.2433 \mathrm{~A}+0.4278 \mathrm{~B}+0.3394 \mathrm{C} \\
& +0.5133 \mathrm{D}+0.1394 \mathrm{AB}-0.2944 \mathrm{AC}-0.2544 \mathrm{AD} \\
& -0.4544 \mathrm{BC}+0.0006 \mathrm{BD}-0.2181 \mathrm{CD}-2.30 \mathrm{~A}^{2} \\
& -1.53 \mathrm{~B}^{2}-1.67 \mathrm{C}^{2}-1.02 \mathrm{D}^{2} .
\end{aligned}
$$

Parameters having positive coefficient values increase $\mathrm{CNC}$ yield whereas parameters with negative coefficient values decrease CNC yield. Results of analysis of variance (ANOVA) are given in Table 3 . The $P$ value less than 0.0500 indicates the model terms are significant. In this case, $\mathrm{A}, \mathrm{B}, \mathrm{C}, \mathrm{D}, \mathrm{AC}, \mathrm{AD}, \mathrm{BC}, \mathrm{A}^{2}, \mathrm{~B}^{2}, \mathrm{C}^{2}$, and $\mathrm{D}^{2}$ are significant model terms. This implies that hydrolysis time, temperature, sulfuric acid concentration, liquid solid ratio, interaction between hydrolysis time and sulfuric acid concentration, interaction between hydrolysis time and liquid solid ratio, and interaction between temperature and sulfuric acid concentration are significant parameters for yield of cellulose nanocrystals produced from BSG. It was observed in Figure 1 that all points are much closed to the line of perfect fit which indicates that the actual and predicted values have closer value. 


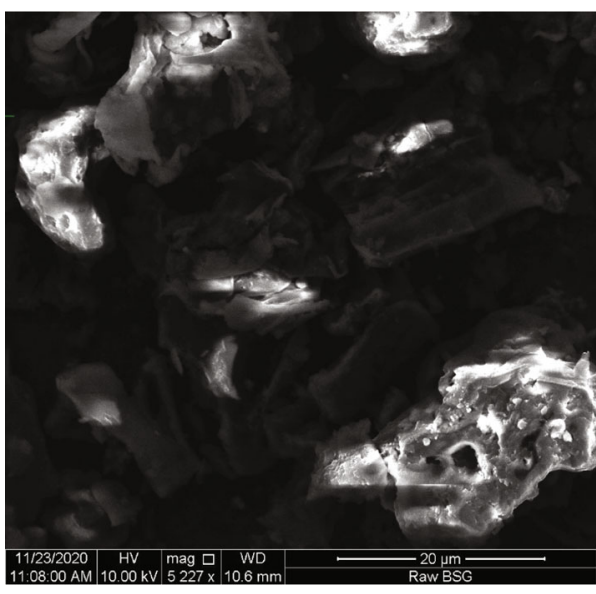

(a)

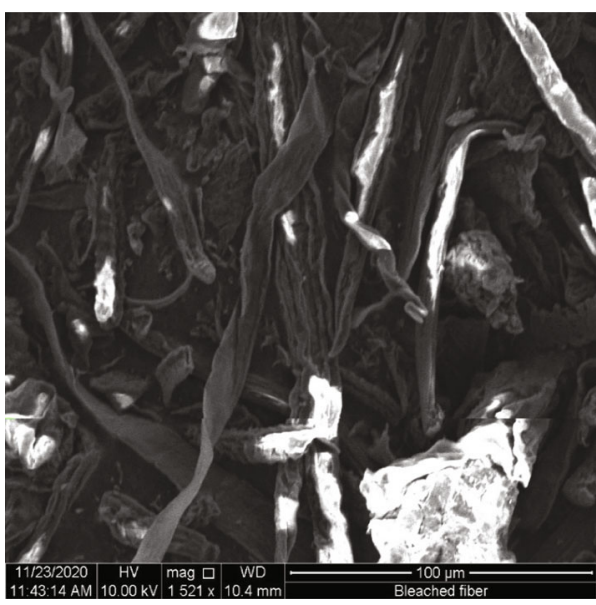

(c)

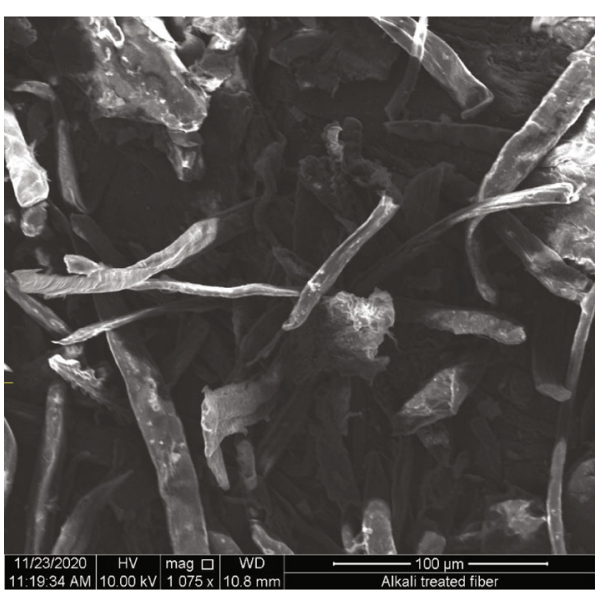

(b)

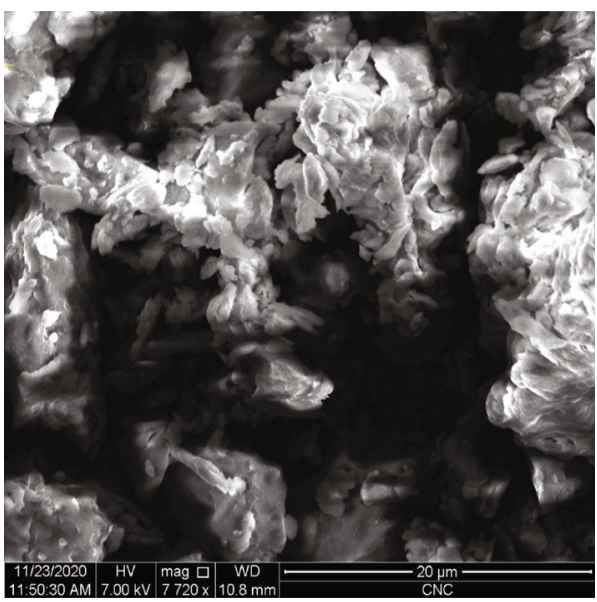

(d)

FIGURE 3: SEM image of (a) BSG fiber, (b) alkali-treated fiber, (c) bleached fiber, and (d) extracted CNCs.

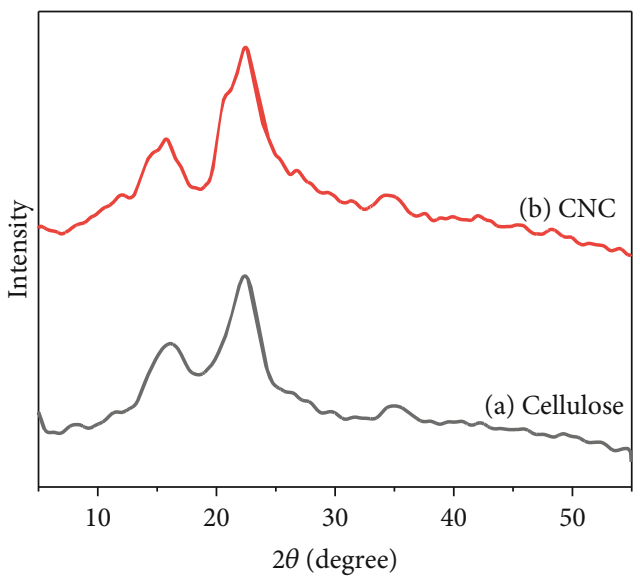

FIGURE 4: X-ray diffraction (XRD) pattern of (a) raw cellulose and (b) CNCs obtained from BSG.

The significant of the regression model with correlation coefficient was determined by depending on $R$-square, adjusted $R$-square, and predicted $R$-square which have a value of $0.9897,0.9765$, and 0.9399 , respectively. The quality of the model developed could be evaluated from their coefficient of relationship. The value shows that the predicted $R$ -square of 0.9399 is in reasonable agreement with the adjusted $R$-square of 0.9765 , i.e., the difference is less than 0.2 . The 0.9897 value of $R$-square shows that $98.97 \%$ of total variation in the percentage of yield of cellulose nanocrystals is attributed to experimental variables studied. As the value of $R$-square is close to unity, the stronger the model predicts the response better. The "Adeq precision" measures the signal to noise ratio. A ratio greater than 4 is desirable. The value of "Adeq precision" for the developed correlation 28.1722 indicates an adequate signal. Thus, the model can be used to navigate the design space.

Cellulose nanocrystal preparation is affected by many parameters starting from sample preparation to bleaching process; the acid hydrolysis process has more relation with independent parameters. Response surface plot and contour plot are the best way to the effect of parameters on the yield of cellulose nanocrystals. In this study, response surface and contour plot were developed using the Design-Expert 12.0.0 software. These plots showed the interaction effect of two parameters on CNC yield by keeping other parameters constant at their middle levels. Circular and elliptical contour 


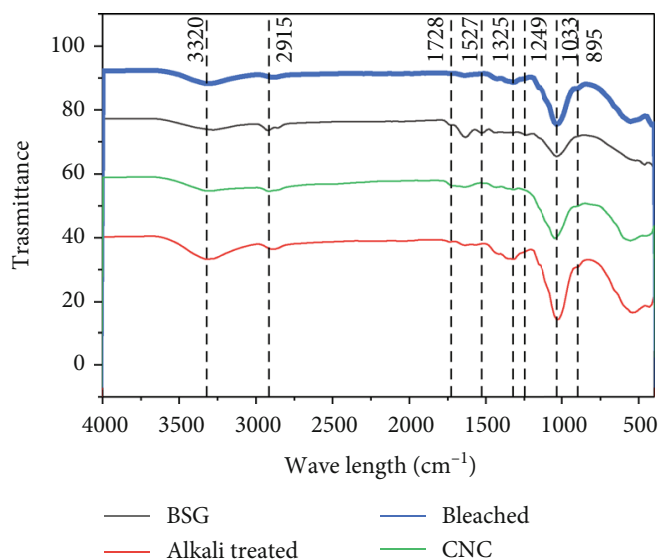

FIGURE 5: FTIR spectra of raw BSG, alkali-treated fiber, bleached fiber, and CNC.

plot shows whether the interaction of parameters is significant or not, which means that circular contour plot implies parameter interaction is insignificant whereas elliptical contour plot indicates parameter interaction is significant [22]. Figure 2(a) presents the interaction effect of hydrolysis time and temperature with acid concentration and liquid-solid ratio maintained constant at $51 \%(\mathrm{w} / \mathrm{v})$ and $20 \mathrm{ml} / \mathrm{g}$, respectively. Figure $2(\mathrm{~b})$ also indicates the effect of time and acid concentration on CNC yield at a constant value of liquid solid ratio and temperature. It was observed that the $\mathrm{CNC}$ yield was changed, when the time changed from 35 to 40 minutes and acid concentration changed from 47 to $51 \%$ $(\mathrm{w} / \mathrm{v})$ and the yield of $\mathrm{CNC}$ reached higher value, while beyond 40 minutes of time and $51 \%(\mathrm{w} / \mathrm{v})$ acid concentration, the yield of CNC was gradually decreased. This occurred due to the over degradation of cellulose in to undesired product at high acid concentration and longer hydrolysis time. Figure 2(c) presents the interaction effect of hydrolysis time and liquid-solid ratio with acid concentration and temperature maintained constant at $51 \%(\mathrm{w} / \mathrm{v})$ and $50^{\circ} \mathrm{C}$, respectively. Figure $2(\mathrm{~d})$ shows the effect of temperature and acid concentration interaction at a fixed value of time and liquid-solid ratio. It was observed that yield of $\mathrm{CNC}$ increased as temperature and acid concentration increased from 45 to $50^{\circ} \mathrm{C}$ and 47 to $51 \%$, respectively, while further increasing of both temperature and acid concentration, the value of $\mathrm{CNC}$ yield becomes decline due to over degradation of cellulose into undesired product at high temperature and acid concentration. Therefore, conducting many experiments at the center point gives optimum yield. Figure 2(e) indicates the effect of liquid-solid ratio and temperature on CNC yield with time and acid concentration kept constant at $40 \mathrm{~min}$ and $51 \%(\mathrm{w} / \mathrm{v})$, while Figure 2(f) shows the effect of liquid-solid ratio and acid concentration interaction at a fixed value of $40 \mathrm{~min}$ of time and $50^{\circ} \mathrm{C}$ steady temperature. Generally, it can be understood that all four variables have important effect on CNC yield.

The optimization was carried out, and its objective was maximizing cellulose nanocrystal yield in a given design space and range of process parameters. Optimization of different combination of process variables was conducted
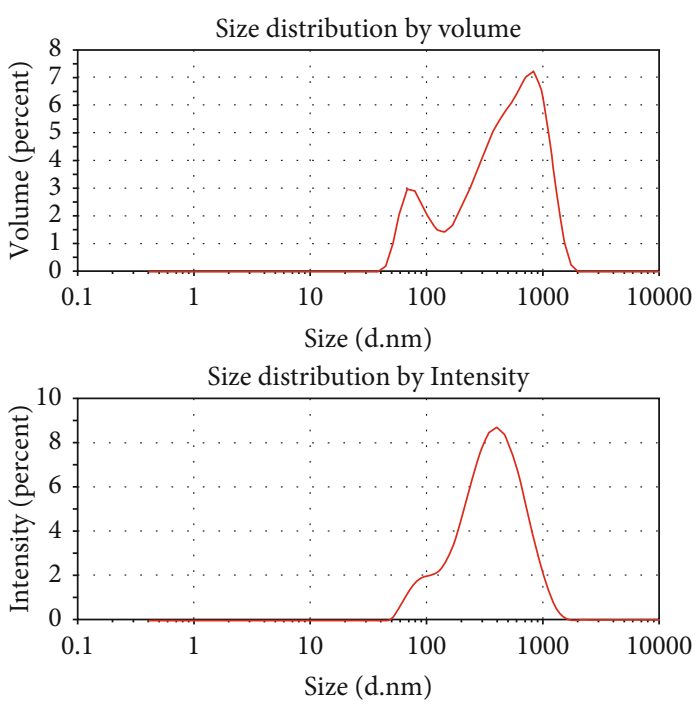

Figure 6: Particle size distribution by volume and intensity.

depending on desirability (D). Numerical optimization and graphical optimization are most common ways for finding optimum response with optimum operating conditions. For this study, numerical optimization and the possible solution of numerical optimization with different interaction of parameters and corresponding desirability value (1.00) were selected. The desirability value helps to identify the maximum and stable response of the experiment. According to numerical optimization solution, the maximum cellulose nanocrystal yield of $43.244 \%$ was achieved at the interaction parameters of $41.07 \mathrm{~min}, 51.088^{\circ} \mathrm{C}, 50.566 \%(\mathrm{w} / \mathrm{v})$ of acid concentration, and $18.794 \mathrm{ml} / \mathrm{g}$ liquid-solid ratio. Hong et al. [1] have isolated CNC from bamboo pulp at optimum parameters of $90 \mathrm{~min}, 60 \%(\mathrm{wt} / \mathrm{v})$ acid concentration, $45^{\circ} \mathrm{C}$, and $8 \mathrm{ml} / \mathrm{g}$ liquid-solid ratio and achieved $32.3 \% \mathrm{CNC}$ yield. Our study indicates a better yield was achieved with minimum time and acid concentration relative to $\mathrm{CNC}$ yield reported in the previous work.

3.2. Scanning Electron Microscope (SEM) Analysis. The morphology of brewery spent grain, alkali-treated fiber, bleached fiber, and CNCs obtained were examined by SEM analysis as shown in Figure 3. Figures 3(a)-3(c) show the SEM micrograph of BSG fiber of untreated, alkali treated, and bleached, respectively. In Figure 3(a), the microstructure of BSG fiber could not be observed clearly. However, the alkali treated and bleached fibers (Figures 3(b) and 3(c)) of the microstructures of the fibers were separately seen. The reason for this was hemicellulose, lignin, and other impurities were successfully removed through chemical treatment. From the image of SEM analysis (Figure 3(d)), it was clearly shown that the microscale cellulose fiber of BSG was effectively reduced to nanoscale through acid hydrolysis and as observed from this image, the extracted cellulose nanocrystals (CNCs) have rod-like whisker-shaped cellulose nanostructure.

3.3. XRD Analysis. The overall crystalline structure of bleached BSG cellulose and extracted CNC samples were 


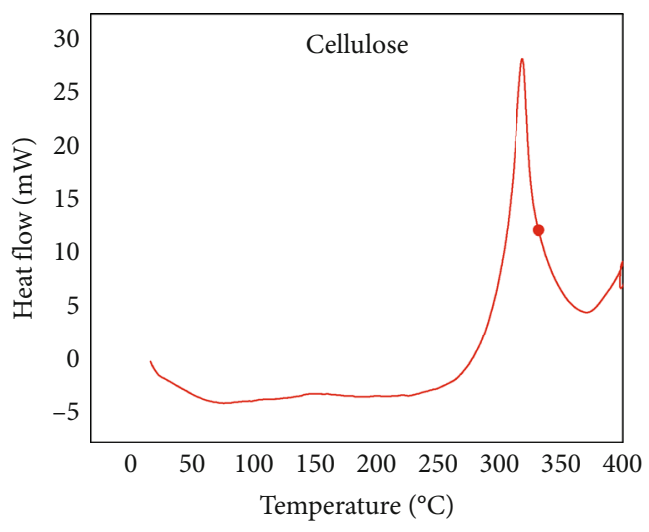

(a)

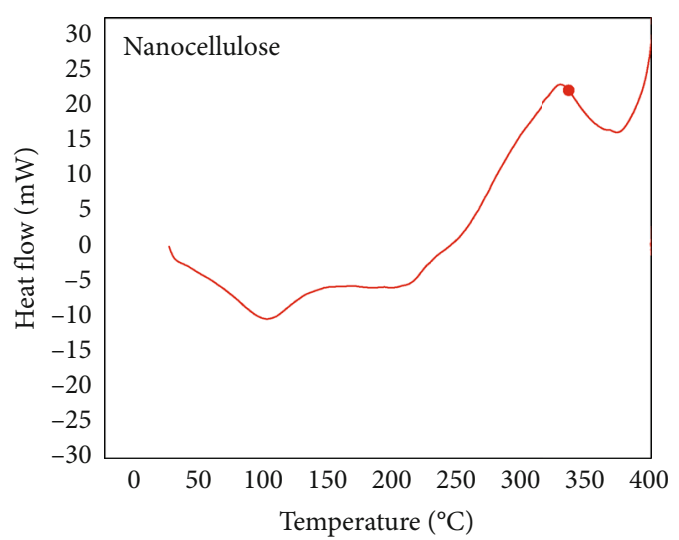

(b)

Figure 7: DSC thermographs for (a) raw cellulose and (b) CNC.

determined by XRD measurement on BTX-528 model diffractometer as shown in Figure 4. The diffraction peak of raw cellulose is relatively broader extracted CNCs. However, the CNC peaks became sharper and narrower due to chemical treatment. According to this pattern, a strong peak appeared at $2 \theta=22.6$ degree was considered for the determination of crystallinity of raw cellulose and CNCs. The crystallinity index and crystal thickness of raw cellulose and CNCs were determined using Equations (1) and (2). The crystallinity of raw cellulose and extracted CNCs as determined by Equation (1) was $64.8 \%$ and $76.3 \%$, respectively. The higher crystallinity value of CNCs compared to cellulose can be well understood by the reduction and removal of amorphous region of cellulose during acid hydrolysis. The crystal size of raw cellulose and obtained CNCs as determined by Equation (2) was $3.08 \mathrm{~nm}$ and $4.97 \mathrm{~nm}$, respectively. In similar study conducted by Hemmati et al. [23], the crystallinity degree of raw cellulose obtained from cotton and resulting CNCs was $62 \%$ and $82 \%$, respectively. Thus, the results of our study were in agreement with this study.

3.4. FTIR Analysis. FTIR analysis of raw BSG, alkali-treated fiber, bleached fiber, and CNCs is given in Figure 5. In the spectrum of all samples, there was a common peak at 3320 $-3290 \mathrm{~cm}^{-1}$ which is related to $\mathrm{OH}$ stretching vibration of cellulose molecules [24]. Comparing the absorption position of bleached fiber and $\mathrm{CNCs}$, the $\mathrm{OH}$ stretching vibration absorption band of CNCs moved toward a lower frequency and the absorption frequency was weakened, which shows that part of intermolecular hydrogen bonding was broken after acid treatment, while intermolecular hydrogen was enhanced. The peak appeared at $1728 \mathrm{~cm}^{-1}$ in the spectrum of untreated BSG attributed to either hemicellulose groups (acetyl and uronic ester group) or lignin groups (ester linkage of carboxylic group of the ferulic and p-coumeric acids). However, this peak almost missed in the spectrum of bleached fiber which shows the removal of lignin and hemicellulose components from BSG through chemical treatment. The peaks observed at $1249 \mathrm{~cm}^{-1}$ and $1527 \mathrm{~cm}^{-1}$ in the spectrum of BSG represent C-O-C (aryl-alkyl ether) and $\mathrm{C}=\mathrm{C}$ aromatic rings of lignin, respectively. These two peaks also vanished after bleaching treatment, which indicates the removal of lignin component from BSG [12]. The peak observed in the spectrum of bleached fiber at $1325 \mathrm{~cm}^{-1}$ was attributed to $\mathrm{S}$ ring $\left(\mathrm{CH}_{2}\right.$ rocking at $\mathrm{C}_{6}$ in cellulose). This peak almost disappeared in the spectrum of $\mathrm{CNC}$, which indicates the developed hydrogen bonding network through acid hydrolysis in the crystalline structure of $\mathrm{CNC}$ decreased shocking movement of $\mathrm{CH}_{2}$. A weak sulfur peak was observed at $1325 \mathrm{~cm}^{-1}$ in CNC, which did not appear in the spectra of BSG bleached fiber. The peaks at $1033 \mathrm{~cm}^{-1}$ are associated with the C-O stretching which is directly related to increase in the cellulosic component. The spectrum at $2915 \mathrm{~cm}^{-1}$ is associated to symmetric and antisymmetric stretching modes of $\mathrm{C}-\mathrm{H}$ in methyl and methylene functional groups. The peak at $895 \mathrm{~cm}^{-1}$ is associated with the presence of typical structure of cellulose due to $\beta$-glycosidic linkage.

3.5. Particle Size Analysis. The particle size measurement was conducted at room temperature with a measurement position of $0.85 \mathrm{~mm}$ and count rate of $45.2 \mathrm{kcps}$. During particle size measurement, glass cuvette was used as cell and a time taken for thermal equilibrium was 170 seconds. It was observed that the average particle size of the obtained cellulose nanocrystals (CNCs) was $309.4 \mathrm{~nm}$. Figure 6 depicts particle size distribution by volume and intensity of obtained CNC. As shown in Figure 6, the obtained cellulose nanocrystals (CNCs) did not present in a uniform size distribution because particles are fragmented during acid hydrolysis [23]. Size distribution by volume shows that CNC particle with smaller size of $86.3 \mathrm{~nm}$ is accountable for $26.7 \%$ of volume. In similar study, Lu and Hsieh [25] have isolated cellulose nanocrystals (CNCs) from rice husk with an average particle size of $700 \mathrm{~nm}$. Brito et al. [26] have also isolated $\mathrm{CNC}$ from bamboo fiber with an average size of $130 \mathrm{~nm}$. The slight difference might be due to variation in raw material used and hydrolysis conditions such as variation in time, temperature, acid type, and liquid-solid ratio.

3.6. Differential Scanning Calorimeter (DSC) Analysis. Figures 7(a) and 7(b) depict the thermal behavior of raw cellulose and extracted cellulose nanocrystals. As shown Figures 7(a) 
and $7(\mathrm{~b})$, the thermographs of an endothermic peak appeared from 28 to $150^{\circ} \mathrm{C}$ due to water evaporation [27]. The exothermic peaks appeared in the thermographs indicate the decomposition point of the raw cellulose and extracted CNC. The exothermic peak of decomposition of raw cellulose shows a sharp peak at $310^{\circ} \mathrm{C}$, whereas the extracted CNCs show a sharp peak at $335^{\circ} \mathrm{C}$. This indicates that the position of peaks increased after chemical treatment. Thus, the resulting CNCs have high thermal stability as compared to the raw cellulose due to acid hydrolysis treatment. The position of peaks mainly depends on the amount of amorphous present in a sample. As we can be observed from peak position of raw cellulose and CNCs, CNCs show higher peak position and this indicates that the amorphous part was removed and the crystallinity was enhanced through chemical treatment.

\section{Conclusion}

High value-added cellulose nanocrystals (CNCs) were successfully extracted from brewery spent grain using acid hydrolysis. The hydrolysis parameters time, temperature, acid concentration, and liquid-solid ratio were investigated to obtain the optimum conditions for the production of cellulose nanocrystals from brewery spent grain. Maximum CNC yield of $43.24 \%$ was obtained at optimum hydrolysis parameters of $41 \mathrm{~min}, 50^{\circ} \mathrm{C}, 51 \mathrm{wt} \%$ acid concentration, and liquid-solid ratio of $19 \mathrm{ml} / \mathrm{g}$.

Characterization of samples was performed, and the result showed that the obtained cellulose nanocrystals have rod-like shape with an average diameter of $309.4 \mathrm{~nm}$. The FTIR and diffraction scanning calorimeter (DSC) analysis indicated that noncellulosic components were successfully removed during pretreatment process, which resulted better thermal stability. The XRD study evidenced that the amorphous region of cellulose was reduced during acid hydrolysis, and the crystallinity was enhanced from $64.6 \%$ to $76.8 \%$. Generally, this study suggested that brewery spent grain can be used as a feedstock for isolation of cellulose nanocrystals for various applications and a better way to minimize environmental effect of brewery spent grain.

\section{Abbreviations}

BSG: Brewery's spent grain

CCD: Central composite design

CI: Crystallinity index

CNCs: Cellulose nanocrystals

D: $\quad$ Crystallinity size

DSC: Diffraction scanning calorimeter

FAO: Food and Agriculture Organization

FTIR: Fourier-transform infrared spectroscopy

RSM: Response surface methodology

SEM: Scanning electron microscopy

XRD: X-ray diffraction.

\section{Data Availability}

All data are available in the manuscript, and further data availability is requested from the corresponding author.

\section{Conflicts of Interest}

Authors declare that they do not have any conflict of interest.

\section{Acknowledgments}

Authors would like to thank Addis Ababa Science and Technology University for allowing experimental set-up work and analytical instrument for characterization.

\section{References}

[1] B. Hong, F. Chen, and G. Xue, "Preparation and characterization of cellulose nanocrystals from bamboo pulp," Cellulose Chemistry and Technology, vol. 50, no. 2, pp. 225-231, 2016.

[2] M. T. Fath and H. Nasution, "Process optimization of manufacturing nanocrystalline cellulose from rattan biomass using sulfuric acid," in AIP Conference Proceedings, vol. 2024, 2018no. 1.

[3] Z. Chowdhury and S. B. A. Hamid, "Preparation and characterization of nanocrystalline cellulose using ultrasonication combined with a microwave-assisted pretreatment process," BioResources, vol. 11, no. 2, pp. 3397-3415, 2016.

[4] A. Musa, M. Ahmad, M. Z. Hussein, and S. M. Izham, “Acid hydrolysis-mediated preparation of nanocrystalline cellulose from rice straw," International Journal of Nanomaterials, Nanotechnology and Nanomedicine, vol. 3, no. 2, pp. 51-56, 2017.

[5] P. Kampeerapappun, "Extraction and characterization of cellulose nanocrystals from corn stover," Journal of Metals, Materials and Minerals, vol. 25, no. 1, pp. 19-26, 2015.

[6] S. I. Mussatto and M. Fernandes, "Lignin recovery from brewer's spent grain black liquor," Carbohydrate Polymers, vol. 70, no. 2, pp. 218-223, 2007.

[7] L. Fillaudeau, B.-A. Pascal, and G. Daufin, "Water, wastewater and waste management in brewing industries," Journal of Cleaner Production, vol. 14, no. 5, pp. 463-471, 2006.

[8] G. Z. Dehnavi, Fractionation of the Main Components of Barley Spent Grains from a Microbrewery, University of Borås, 2009.

[9] I. Shahabi-Ghahfarrokhi, F. Khodaiyan, M. Mousavi, and H. Yousefi, "Preparation and characterization of nanocellulose from beer industrial residues using acid hydrolysis/ultrasound," Fibers and Polymers, vol. 16, no. 3, pp. 529-536, 2015.

[10] D. Tang, G. Yin, Y.-Z. He et al., "Recovery of protein from brewer's spent grain by ultrafiltration,” Biochemical Engineering Journal, vol. 48, no. 1, pp. 1-5, 2009.

[11] S. Aliyu and M. Bala, "Brewer' s spent grain : a review of its potentials and applications," African Journal of Biotechnology, vol. 10, no. 3, pp. 324-331, 2011.

[12] D. M. Santos, A. L. Bukzem, D. P. R. Ascheri, R. Signini, and G. L. B. Aquino, "Microwave-assisted carboxymethylation of cellulose extracted from brewer's spent grain," Carbohydrate Polymers, vol. 131, no. 2015, pp. 125-133, 2015.

[13] A. Sharma, M. Thakur, M. Bhattacharya, T. Mandal, and S. Goswami, "Commercial application of cellulose nanocomposites - A review," Biotechnology Reports, vol. 21, p. e00316, 2019. 
[14] P. Phanthong, P. Reubroycharoen, X. Hao, G. Xu, A. Abudula, and G. Guan, "Nanocellulose: Extraction and application," Carbon Resources Conversion, vol. 1, no. 1, pp. 32-43, 2018.

[15] R. S. A. Ribeiro, B. C. Pohlmann, V. Calado, N. Bojorge, and N. Pereira Jr., "Production of nanocellulose by enzymatic hydrolysis : trends and challenges," Engineering in Life Sciences, vol. 19, no. 4, pp. 279-291, 2019.

[16] S. Ren, X. Sun, T. Lei, and Q. Wu, "The effect of chemical and high-pressure homogenization treatment conditions on the morphology of cellulose nanoparticles," Journal of Nanomaterials, vol. 2014, Article ID 582913, 11 pages, 2014.

[17] H. Xie, D. Haishun, X. Yang, and S. Chuanling, "Recent strategies in preparation of cellulose nanocrystals and cellulose nanofibrils derived from raw cellulose materials," International Journal of Polymer Science, vol. 2018, Article ID 7923068, 25 pages, 2018.

[18] M. Santos, J. J. Jiménez, B. Bartolomé, C. Gómez-Cordovés, and M. J. Del Nozal, "Variability of brewer's spent grain within a brewery," Food Chemistry, vol. 80, no. 1, pp. 17-21, 2003.

[19] S. I. Mussatto, G. J. M. Rocha, and I. C. Roberto, "Hydrogen peroxide bleaching of cellulose pulps obtained from brewer's spent grain," Cellulose, vol. 15, no. 4, pp. 641-649, 2008.

[20] I. K. Al-khateeb, S. M. Hussin, and Y. M. Al-obaidi, "Extraction of cellulose nano crystalline from cotton by ultrasonic and its morphological and structural characterization," International Journal of Materials Chemistry and Physics, vol. 1, no. 2, pp. 99-109, 2019.

[21] S. Maiti, J. Jayaramudu, K. Das et al., "Preparation and characterization of nano-cellulose with new shape from different precursor," Carbohydrate Polymers, vol. 98, no. 1, pp. 562-567, 2013.

[22] G. Kandhola, A. Djioleu, K. Rajan et al., "Maximizing production of cellulose nanocrystals and nanofibers from preextracted loblolly pine kraft pulp: a response surface approach," Bioresources and Bioprocessing, vol. 7, no. 1, 2020.

[23] F. Hemmati, S. M. Jafari, and R. A. Taheri, "Optimization of homogenization-sonication technique for the production of cellulose nanocrystals from cotton linter," International Journal of Biological Macromolecules, vol. 137, pp. 374-381, 2019.

[24] M. El Achaby, Z. Kassab, A. Aboulkas, C. Gaillard, and A. Barakat, "Reuse of red algae waste for the production of cellulose nanocrystals and its application in polymer nanocomposites," International Journal of Biological Macromolecules, vol. 106, pp. 681-691, 2018.

[25] P. Lu and Y.-L. Hsieh, "Preparation and characterization of cellulose nanocrystals from rice straw," Carbohydrate Polymers, vol. 87, no. 1, pp. 564-573, 2012.

[26] B. L. Brito, F. Pereira, J.-L. Putaux, and B. Jean, "Preparation, morphology and structure of cellulose nanocrystals from bamboo fibers," Cellulose, vol. 19, no. 5, pp. 1527-1536, 2012.

[27] J. Moran, V. Alvarez, V. Cyras, and A. Vazquez, "Extraction of cellulose and preparation of nanocellulose from sisal fibers," Cellulose, vol. 15, no. 1, pp. 149-159, 2008. 